\title{
The Effect of Apple Juice on Antioxidant Enzymes and Lipid Profiles in Orchidectomized Rats
}

\author{
Mahmood Abedinzade ${ }^{1,4}$; Katayoon Harialchi ${ }^{2}$; Korosh Khanaki ${ }^{3}$; Mahmood Khosravi ${ }^{4}$; \\ Mojtaba Farahbakhsh ${ }^{3}$ \\ ${ }_{1}^{1}$ Department of Physiology, Faculty of Paramedicine, Guilan University of Medical sciences, Rasht, IR Iran \\ ${ }^{2}$ Department of Anesthesiology, Faculty of Paramedicine, Guilan University of Medical sciences, Langrood Rasht, IR Iran \\ ${ }^{3}$ Department of Biochemistry, Faculty of Paramedicine, Guilan University of Medical sciences, Rasht, IR Iran \\ 4 Depart \\ ${ }^{*}$ Corresponding author: Mahmood Abedinzade, Department of Physiology, Faculty of Paramedicine, Guilan University of Medical sciences, Rasht, IR Iran. Tel: +98-9111496277, E-mail: \\ mahmood.abedinzade@gmail.com
}

Received: April 11, 2014; Accepted: June 14, 2014

Background: The age-dependent worsening of lipid profiles increased the risk of cardiovascular disease in males. Eating fruits and vegetables is known to be beneficial on lipid profile.

Objectives: The objective of this research was to delineate whether drinking daily squeezed apple juice (AJ) modulates lipid profile and antioxidant enzymes in the animal model that gonadectomized.

Materials and Methods: In this experimental study, 28 male rats were equally divided among the following 4 groups: group I (control), orchidectomized (ORX), ORX $+\mathrm{AJ} 10 \%$, and ORX+ AJ 25\%. After 60 days of drinking AJ, superoxide dismutase (SOD), alkaline phosphatase (ALP), cholesterol, LDL, HDL and triglycerides in serum were evaluated. Data analyzed by SPSS-16 and computed using one way ANOVA followed by Tukey multiple comparison test. $\mathrm{P}<0.05$ was statistically significant.

Results: In the ORX group compared with the sham group serum SOD and ALP activities decreased $(\mathrm{P}<0.05)$, while serum cholesterol, triglycerides, LDL increased but HDL decreased in ORX groups $(\mathrm{P}<0.05)$. In contrast to the ORX group, drinking AJ decreased $(\mathrm{P}<0.05)$ concentration of LDL, TG and cholesterol in the serum. AJ also increased $(\mathrm{P}<0.05)$ serum HDL, SOD and ALP activities compared with the ORX group.

Conclusions: Drinking AJ prevented oxidative stress by elevating serum antioxidant enzymes.

Keywords: Antioxidants; Cholesterol; Malus; Rats

\section{Background}

The high incidence of atherosclerosis in elderly people suggests that ageing process may be among the factors that disturb lipid metabolism; hence put elderly subjects at risk of developing cerebrovascular and/or coronary heart diseases. Actually, previous reports proposed that human with exceptional longevity have significantly larger high density lipoproteins (HDL). This in turn decreases prevalence of hypertension, the metabolic syndrome, cerebrovascular diseases and other fatal diseases which usually causes death in elderly people (1). While the incidence of CVD is significantly lower among young men, it increases exponentially in older men. Jones et al. suggest that one of the main reasons is related to a decline in serum levels of testosterone with aging, which contributes to the atherosclerotic process Low levels of serum testosterone, are linked with several cardiovascular risk factors, including hyper cholesterolemia, dyslipidemia and insulin resistance (2).

Accumulated findings suggest that eating fruit and vegetables is beneficial against CVD (3-6). Positive effects of fruits and vegetables have been attributed to dietary fibers, antioxidants, and especially phenolic compounds (7). Fibers and polyphenols are capable of improving the lipid profile in cardiovascular patients (8). Apple is one of those fruits which can play a role in decreasing the risk of chronic diseases, because of the fiber and chemical components such as flavonoids, polyphenols and carotenoids $(9,10)$. For example, orange juice (OJ) and grapefruit juice (GJ) were shown to be rich sources of antioxidants and polyphenols, and they cooperatively reduced oxidative stress and blood lipid profiles, making them a valuable choice for disease prevention in particular among the elderly $(11,12)$. Apple is one of those fruits which can play a role in decreasing the risk of chronic diseases, because of the fiber and chemical components such as flavonoids, polyphenols and carotenoids (8).

\section{Objectives}

Importance of apple can be explained by different factors including their availability in the market throughout the

Copyright (C) 2015, Zahedan University of Medical Sciences. This is an open-access article distributed under the terms of the Creative Commons Attribution-NonCommercial 4.0 International License (http://creativecommons.org/licenses/by-nc/4.0/) which permits copy and redistribute the material just in noncommercial usages, provided the original work is properly cited. 
year in a variety of forms (fresh fruit, juice, cider, mashed apples) and also their reputation as a healthy food, therefore, we decided to assess the effect of apple juice on lipid profile and antioxidant enzymes in gonadectomized rat.

\section{Materials and Methods}

In this experimental study, 28 male Sprague Daley rats weighing 280-320 g purchased from breeding and maintaining laboratory animal's center of Guilan University of Medical Sciences. After transferring rats to paramedical faculty, they were kept in animal room for 7 to 15 days so that they yet close their ideal weight in addition to having adaptation with environment. During study, rats kept in animal room under 12 - 12 hour light/dark cycle and in $22 \pm 1^{\circ} \mathrm{C}$.

The rats were randomly divided into 4 groups $(\mathrm{N}=7$ for each group):

1) Group I: As control group, did not receive any treatment.

2) Group II: Rats gonadectomized and did not receive any treatment.

3) Group III: Rats gonadectomized and received apple juice with $10 \%$ concentration.

4) Group IV: Rats gonadectomized and received apple juice with $25 \%$ concentration.

The rats were anesthetized by ketamine and xylazine (100 mg/kg and $5 \mathrm{mg} / \mathrm{kg}$ respectively) and in sterile conditions, the incision made in the pelvic area, the testes were removed. Three days after surgery diet with natural extracts are listed. All of the animals were weight, water intake and food consumption was measured during the 60 -day period. After 60 days, blood samples were taken from the tail vein and the animals were killed by i.p. injection of pentobarbital. I hereby certify that the procedures and the experiments I have done respect the ethical standards in the Helsinki declaration of 1975, as revised in 2000 , as well as the care of experimental animals com- plies with national institutes of health guidelines for the human use of laboratory animals.

Laboratory evaluations: Blood samples were placed in heparinated tubes and centrifuged for $15 \mathrm{~min}$ with acceleration g 1500. Plasma was separated and the next step freezed in $-20^{\circ} \mathrm{C}$ and then were measured by the kit for superoxide dismutase (SOD) (Boster Inc., Shanghai, China) and alkaline phosphatase (ALP) levels by kit (Boster Inc., Shanghai, China) and both were determined by ELISA. Concentration of triglyceride, total cholesterol (TC), LDL$\mathrm{C}$, and HDL-C were measured by an enzymatic method, using "Pars Azemoon" commercial kits (manufactured in Tehran, Iran, under the license of German Herb company).

Statistical analysis: All data expressed as Mean \pm SD and for statistical analysis, SPSS-16 was used. Data were computed using one-way ANOVA followed by Tukey multiple comparison tests. P values less than 0.05 was considered meaningful level. This research has been conducted in compliance with all ethical issue.

\section{Results}

Weight: in all groups, final body weights compared to initial weight increased dramatically $(\mathrm{P}=0.001)$, but not significant differences were seen in food intake and drinking water of all groups. Compared with the control group, the group II showed a significant $(\mathrm{P}=0.008)$ decrease in SOD and ALP activities (Table 1). However, SOD and ALP activities were significantly higher $(\mathrm{P}=0.011)$ in rats drinking apple juice compared with the ORX group drinking water. The concentration of triglycerides, cholesterol, and LDL in the serum numerically increased $(\mathrm{P}=$ 0.001) in the group II in comparison to the control group. In contrast, rats that drank AJ exhibited decrease in mentioned parameter in serum compared with the group II. Compared with the control group, concentrations of HDL in serum of the group II decreased dramatically and in AJ groups $(10 \%, 25 \%)$ HDL increased significantly $(\mathrm{P}=0.015)$.

\begin{tabular}{|c|c|c|c|c|}
\hline Variable & Group I & Group II & Group III & Group IV \\
\hline \multicolumn{5}{|l|}{ Body weight } \\
\hline Initial & $230 \pm 7$ & $242 \pm 8$ & $238 \pm 6$ & $251 \pm 13$ \\
\hline Final & $275 \pm 9$ & $271 \pm 11$ & $278 \pm 7$ & $290 \pm 11$ \\
\hline Food intake & $22 \pm 0.6$ & $21 \pm 0.4$ & $21 \pm 0.3$ & $21 \pm 0.3$ \\
\hline Drinking water & $31 \pm 7$ & $26 \pm 4$ & $23 \pm 4$ & $27 \pm 4$ \\
\hline
\end{tabular}

a Data are presented as mean \pm SD.

b $\mathrm{P}<0.05$, significant difference with control group.

\begin{tabular}{lccc}
\hline \multicolumn{2}{l}{ Table 2. Evaluation of SOD and ALP Concentration in All Groups $\mathrm{a}, \mathrm{b}$} \\
\hline Variable & Group I & Group II & Group III \\
\hline Plasma SOD, U/L & $143 \pm 5$ & $126 \pm 6^{\mathrm{C}}$ & $142 \pm 7^{\mathrm{d}}$ \\
Plasma ALP, U/L & $61 \pm 6.1$ & $85 \pm 5.95^{\mathrm{C}}$ & $47 \pm 4.67^{\mathrm{d}}$ \\
\hline
\end{tabular}

a Abbreviations: ALP, alkaline phosphatase; SOD, superoxide dismutase.

b Data are presented as mean \pm SD.

c $\mathrm{P}<0.05$, significant difference with control group.

$\mathrm{d}_{\mathrm{P}<0.05}$, significant difference with Group II. 
Abedinzade $M$ et al.

\begin{tabular}{lcccc}
\hline Table 3. Assessment Lipid Profile in All Groups & & & \\
\hline Groups & TG & HDL & LDL & TC \\
\hline Group I & $94.5 \pm 2.1$ & $43.7 \pm 1.7$ & $38.2 \pm 1.39$ & $80.8 \pm 1.95$ \\
Group II & $128 \pm 3.3^{\mathrm{C}}$ & $33.2 \pm 1.22^{\mathrm{C}}$ & $58.3 \pm 1.58^{\mathrm{C}}$ & $122.5 \pm 1.19^{\mathrm{C}}$ \\
Group III & $113.5 \pm 1.3^{\mathrm{d}}$ & $37.2 \pm 1.7^{\mathrm{d}}$ & $47.5 \pm 1.6^{\mathrm{d}}$ & $111.1 \pm 1.4^{\mathrm{d}}$ \\
Group IV & $102.5 \pm 1.7^{\mathrm{d}}$ & $39 \pm 1.9^{\mathrm{d}}$ & $42 \pm 1.3^{\mathrm{d}}$ & $104.8 \pm 1.61^{\mathrm{d}}$ \\
\hline
\end{tabular}

a Abbreviations: HDL, high density lipoprotein; LDL, low density lipoprotein ; TG, triglyceride; TC, total cholesterol.

b Data are presented as mean \pm SD.

C $\mathrm{P}<0.05$, significant difference with control group.

$\mathrm{d}$ P $<0.05$, significant difference with Group II.

\section{Discussion}

In the present study, apple juice $10 \%$ and $25 \%$ could increase antioxidant enzymes levels (SOD and ALP) in gonadectomized rats. Apple juice also decrease the level of LDL, TG and cholesterol and increase the concentration of HDL in groups III and IV that treated by this extract.

Tam et al. showed that testosterone depletion induces oxidative stress and attenuates antioxidant levels (13). In a similar study, an increase in the plasma antioxidant activity was observed in rats receiving either fresh OJ or GJ. The authors attributed the high antioxidant capacity largely to the bioactive compounds (14). In another study, rats that ate a diet rich in cholesterol while drinking either red GJ or naringin exhibited a higher antioxidant capacity than the control group (15). A recent animal study has reported that in mice, naringin reduced lipid peroxidation status in tissues by enhancing tissue antioxidant status (16). Barp et al. (17) and Azevedo et al. (18) reported that castration decreases SOD and CAT levels. The data reported here suggest that orchidectomy modulates the antioxidant enzymes while citrus juices prevent activities of liver antioxidant enzymes from being depressed. Furthermore, in comparison with the sham group, drinking citrus juice in gonadectomized rats prevented total antioxidant status and liver SOD and CAT activities from decreasing, suggesting natural products from dietary components prevent free radical accumulation $(17,18)$. In the present study, gonadectomy increased LDL, TG and cholesterol levels and HDL concentration but apple juice could reverse this situation. In a study by Dennison et al. consumption of 5.5 ounces (158.7 g) fruit juice including a mixture of 35\% (1.8 ounces) apple juice, 31\% (1.5 ounces) orange juice, $25 \%$ (1.3 ounces) grape juice and $9 \%$ other types of fruit juices caused no significant difference on the level of TG, TC, LDL-C and Lp (a) (19).

In a study by Nagasako-Akazome et al. a daily intake of $600 \mathrm{mg}$ apple polyphenol extract caused a significant decrease of serum TC and LDL-C22 (10). In several animal studies, when normolipidemic rats and diet-induced hyperlipidemic rats were given flavanones, the triglyceride level in serum or plasma was reduced $(20,21)$. In another study in ovariectomized mice, a diet containing $0.5 \%$ hesperidin decreased serum and hepatic triglyceride concentrations compared with the control diet (22). It is likely that bioactive compounds from OJ and GJ mediated the low triglyceride concentration in liver. However, the potential benefits of these bioactive compounds may be mediated by inhibition of the activity of 3-hydroxy3-methylglutaryl-CoA reductase and acyl-CoA: cholesterol acyl transferase, causing a net decrease in hepatic cholesterol synthesis. In conclusion, frequent drinking of AJ can be used as a nonpharmacologic protective agent that enhances total antioxidant status and antioxidant enzymes while it reduces oxidative stress in hypogonadal rats. Furthermore, hypolipidemic and hypocholesterolemic effects of daily drinking of AJ can significantly protect against atherosclorosis.

\section{Acknowledgements}

Efforts of Dr. Nikokar and Dr. Qasemzadeh are highly appreciated. Project number: 57/132, project manager: Dr. Abedinzade.

\section{Funding/Support}

Guilan University of Medical Sciences.

\section{References}

1. Marhoum TA, Abdrabo AA, Lutfi MF. Effects of age and gender on serum lipid profile in over 55 years-old apparently healthy Sudanese individuals. Asian J Biomed Pharm Sci. 2013;3(19):10-4.

2. Jones RD, Nettleship JE, Kapoor D, Jones HT, Channer KS. Testosterone and atherosclerosis in aging men: purported association and clinical implications. Am J Cardiovasc Drugs. 2005;5(3):141-54.

3. Rissanen $\mathrm{TH}$, Voutilainen $\mathrm{S}$, Virtanen JK, Venho B, Vanharanta M, Mursu J, Salonen JT, et al. Low intake of fruits, berries and vegetables is associated with excess mortality in men: the Kuopio Ischaemic Heart Disease Risk Factor (KIHD) Study. J Nutr. 2003;133(1):199-204.

4. Liu S, Manson JE, Lee IM, Cole SR, Hennekens CH, Willett WC Buring JE, et al. Fruit and vegetable intake and risk of cardiovascular disease: the Women's Health Study. Am J Clin Nutr. 2000;72(4):922-8

5. Joshipura KJ, Ascherio A, Manson JE, Stampfer MJ, Rimm EB, Speizer FE, Hennekens CH, Spiegelman D, Willett WC, et al. Fruit and vegetable intake in relation to risk of ischemic stroke. JAMA. 1999;282(13):1233-9.

6. Bazzano LA, He J, Ogden LG, Loria CM, Vupputuri S, Myers L, Whelton PK, et al. Fruit and vegetable intake and risk of cardiovascu- 
lar disease in US adults: the first National Health and Nutrition Examination Survey Epidemiologic Follow-up Study. Am J Clin Nutr. 2002;76(1):93-9.

7. Alvarez-Parrilla E, De La Rosa LA, Legarreta P, Saenz L, RodrigoGarcia J, Gonzalez-Aguilar GA. Daily consumption of apple, pear and orange juice differently affects plasma lipids and antioxidant capacity of smoking and non-smoking adults. Int J Food Sci Nutr. 2010;61(4):369-80.

8. Basu A, Rhone M, Lyons TJ. Berries: emerging impact on cardiovascular health. Nutr Rev. 2010;68(3):168-77.

9. Boyer J, Liu RH. Apple phytochemicals and their health benefits. NutrJ. 2004;3:5.

10. Nagasako-Akazome Y, Kanda T, Ohtake Y, Shimasaki H, Kobayashi T. Apple polyphenols influence cholesterol metabolism in healthy subjects with relatively high body mass index. J Oleo Sci. 2007;56(8):417-28.

11. Kiefer I, Prock P, Lawrence C, Wise J, Bieger W, Bayer P, Rathmanner T, Kunze M, Rieder A, et al. Supplementation with mixed fruit and vegetable juice concentrates increased serum antioxidants and folate in healthy adults. J Am Coll Nutr. 2004;23(3):205-11.

12. Densupsoontorn N, Jirapinyo P, Thamonsiri N, Wongarn R, Phosuya P, Tritiprat A, Patraarat S, Pidatcha P, Suwannthol L, et al. Comparison of the nutrient content of fresh fruit juices vs commercial fruit juices. J Med Assoc Thai. 2002;85 Suppl 2:S732-8.

13. Tam NN, Gao Y, Leung YK, Ho SM. Androgenic regulation of oxidative stress in the rat prostate: involvement of $\mathrm{NAD}(\mathrm{P}) \mathrm{H}$ oxidases and antioxidant defense machinery during prostatic involution and regrowth. Am J Pathol. 2003;163(6):2513-22.

14. Gorinstein S, Leontowicz H, Leontowicz M, Krzeminski R, Gralak M, Martin-Belloso O, Delgado-Licon E, Haruenkit R, Katrich E, Park YS, Jung ST, Trakhtenberg S, et al. Fresh Israeli Jaffa blond (Shamouti) orange and Israeli Jaffa red Star Ruby (Sunrise) grapefruit juices affect plasma lipid metabolism and antioxidant capacity in rats fed added cholesterol. J Agric Food Chem. 2004;52(15):4853-9.

15. Gorinstein S, Leontowicz H, Leontowicz M, Krzeminski R, Gralak M, Delgado-Licon E, Martinez Ayala AL, Katrich E, Trakhtenberg S, et al. Changes in plasma lipid and antioxidant activity in rats as a result of naringin and red grapefruit supplementation. J Agric Food Chem. 2005;53(8):3223-8.

16. Jagetia GC, Reddy TK. Modulation of radiation-induced alteration in the antioxidant status of mice by naringin. Life Sci. 2005;77(7):780-94.

17. Barp J, Araujo AS, Fernandes TR, Rigatto KV, Llesuy S, Bello-Klein A Singal P, et al. Myocardial antioxidant and oxidative stress changes due to sex hormones. Braz J Med Biol Res. 2002;35(9):1075-81.

18. Azevedo RB, Lacava ZG, Miyasaka CK, Chaves SB, Curi R. Regulation of antioxidant enzyme activities in male and female rat macrophages by sex steroids. Braz J Med Biol Res. 2001; 34(5):683-7.

19. Dennison BA, Rockwell HL, Nichols MJ, Jenkins P. Children's growth parameters vary by type of fruit juice consumed. $\mathrm{J} \mathrm{Am}$ Coll Nutr. 1999;18(4):346-52.

20. Monforte MT, Trovato A, Kirjavainen S, Forestieri AM, Galati EM, Lo Curto RB. Biological effects of hesperidin, a Citrus flavonoid. (note II): hypolipidemic activity on experimental hypercholesterolemia in rat. Farmaco. 1995;50(9):595-9.

21. Kurowska EM, Manthey JA. Hypolipidemic effects and absorption of citrus polymethoxylated flavones in hamsters with diet-induced hypercholesterolemia. J Agric Food Chem. 2004;52(10):2879-86.

22. Kawaguchi K, Mizuno T, Aida K, Uchino K. Hesperidin as an inhibitor of lipases from porcine pancreas and Pseudomonas. Biosci Biotechnol Biochem. 1997;61(1):102-4. 